Table Diagnoses and number of cases

\begin{tabular}{|c|c|c|c|}
\hline \multicolumn{2}{|l|}{ Neurological patients } & \multicolumn{2}{|l|}{ Psychiatric patients } \\
\hline Diagnosis & Number & Diagnosis & Number \\
\hline Sleep diorders & 4 & Affective disorders & 19 \\
\hline Multiple sclerosis & 3 & Schizophrenic disorders & 39 \\
\hline Central nervous system neoplasms & 5 & Paranoia & 4 \\
\hline Meningitis & 7 & Brief reactive psychosis & 9 \\
\hline Viral encephalitis & 3 & Neuroses & 18 \\
\hline Extrapyramidal diseases & 9 & Adjustment disorders & 5 \\
\hline Infantile cerebral palsy & 5 & Personality disorders & 6 \\
\hline Infantile spinal muscle & 3 & Organic mental disorders & 10 \\
\hline atrophy & & Substance use disorders & 5 \\
\hline Peripheral nervous & 14 & Other psychiatric disorders & 8 \\
\hline system diseases & & Total & 123 \\
\hline Epilepsy & 20 & & \\
\hline Other neurological diseases & 6 & & \\
\hline Total & 79 & & \\
\hline
\end{tabular}

taurocyamine at a concentration of $200 \mathrm{nmol}$. A small peak, perhaps urea, is seen after 40 minutes. Quantitative determination of taurocyamine is not without problems and overestimation can occur. ${ }^{9}$ Taurocyamine could not be estimated in any CSF of the patients examined. This means that high levels of taurocyamine as described in CSF of uraemic patients ${ }^{3}$ can be ruled out for patients with neurological and psychiatric diseases.

P WIECHERT*
P DE DEYN +
B MARESCAU +
A LOWENTHAL
*Clinic of Psychiatry and
Neurology, W Pieck University of
Rostock, GDR
+Laboratory of Neurochemistry,
Born-Bunge Foundation,
University of Antwerp,
2610 Antwerp, Belgium

References

${ }^{1}$ Mori A, Katayama Y, Yokoi I, Matsumoto M. Inhibition of taurocyamine (guanidinotaurine)-induced seizures by taurine. In: Schaffer SW, Baskin SI, Kocsis JJ, eds. The Effects of Taurine on Excitable Tissues. New York: Spectrum Publications, 1981:41-8.

${ }^{2}$ Rao A, Balgia L, Raja A, Rao SN. Urinary excretion of taurine in epilepsy. Acta Neurol Scand 1983;68:421-3.

${ }^{3}$ Yamamoto Y, Saito A, Manji T, Nishi H, Ito K, Maeda K, Ohta K, Kobayashi K. A new automated analytical method for guanidino compounds and their cerebrospinal fluid levels in uremia. Trans Am Soc Intern Organs 1978;24:61-8.

${ }^{4}$ Mori A, Wantanabe Y, Akagi M. Guanidino compound anomalies in epilepsy. In: Akimoto $H$, Kazamatsuri $H$, Seino $M$, Ward A, eds. Advances in Epileptology: XIIIth Epilepsy International Symposium. New York: Raven Press, 1982:347-51.
${ }^{5}$ Mori A, Watanabe Y, Fukimoto N. Fluorometrical analysis of guanidino compounds in human cerebrospinal fluid. $J$ Neurochem 1982;38:448-50.

${ }^{6}$ The International Classification of Diseases. 9th revision. Department of Health and Human Services Washington DC, 1980, publication No (PMS) 80-1260 US.

${ }^{7}$ Diagnostic and statistical Manual of Mental disorders. Third Edition. Spitzer RL, et al eds. Washington, The American Psychiatric Association, 1980, Library of Congress Catalogue Number 79-055868.

${ }^{8}$ Durzan DI. Automated chromatographic analysis of free monosubstituted guanidines in physiological fluids. Can $J$ Biochem 1969;47:657-64.

${ }^{9}$ Marescau B, De Deyn P, Wiechert P, Van Gorp L, Lowenthal A. Quantitative overestimation of free taurocyamine using short liquid cation exchange chromatography columns? J Chromatogr 1985;345:215-7.

\section{Familial carpal and tarsal tunnel syndrome}

Sir: The familial occurrence of nerve entrapment at the carpal and tarsal tunnel seems to have been rarely if ever described. Pedigrees of families liable to pressure palsies $^{1}$ have included evidence of subclinical abnormalities under the carpal tunnel but these patients had symptomatic palsies predominantly of the sciatic and ulnar nerves. We have recently studied a patient whose family members show a predilection to either the carpal tunnel syndrome or the tarsal tunnel syndrome.

A 61-year-old housewife was referred to one of us (MLS) with a history of pain in the foot on both sides characteristic of the tarsal tunnel syndrome. She was otherwise healthy, of average build without notably abnormal wrists or ankles. Electrophysiological study confirmed local abnor- mality, ${ }^{2}$ and significant asymmetry of the distal latencies to flexor hallucis and 으 abductor quinti minimi. ${ }^{3}$ A sural sensory $Z$ action potential was normal in amplitude and latency. The patient had had successful surgery for bilateral carpal tunnel syndrome. She had four sisters: one was asymptomatic. An elder sister had been treated for unilateral carpal tunnel syndrome, as had one younger sister. The youngest in the family, a woman aged 43 years, had had treatment for a unilateral carpal tunnel syndrome and a unilateral tarsal tunnel $\Rightarrow$ syndrome. The patient's mother had just $\stackrel{\oplus}{+}$ been diagnosed as having the carpal tunnel $\bar{C}$ syndrome. Unfortunately these other members of her family do not live in the UK and could not be examined.

This family show a striking predisposition to entrapment at the carpal tunnel and at the $\infty$ tarsal tunnel. There was no obvious abnor- $\overrightarrow{0}$ mality of the wrists or ankles of the patient examined, and no stigmata of any con- $\vec{\omega}$ nective tissue or skeletal disease. The other family members are not thought to be abnormal in any other way. Nevertheless it seems likely that the cause lies in the geometry of the carpal and tarsal tunnels, rathep than undue nerve sensitivity to pressure ô stretch since none of the family membef $\vec{V}$ gave a history of other nerve pressure palsies and the patient studied had no evidence of $\frac{9}{8}$ diffuse neuropathy. Computed tomograph of the wrists has shown that patients wit the carpal tunnel syndrome have a smalle than normal space. ${ }^{4}$ The occasional coin $\overrightarrow{0}$ cidence of the carpal tunnel syndrome ant $\infty$ tarsal tunnel syndrome has been reported before, ${ }^{5}$ but not its familial incidence.

CP FOWLER * MJG HARRISON* ML SNAITH†

Department of Neurological Studies, ${ }^{*}$ Department of Rheumatology and Rehabilitation, $\dagger$ The Middlesex and University College Hospitals, London, UK

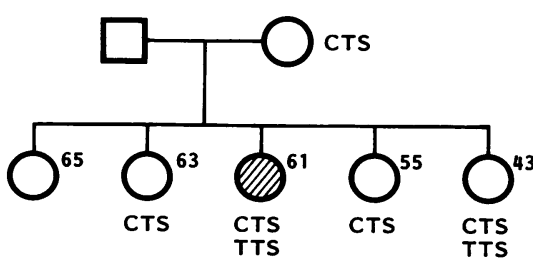

Fig Pedigree of family. Square = male, circle $=$ female, black symbol $=$ propositus, CTS = carpal tunnel syndrome, $T T S=$ tarsal tunnel syndrome, numbers $=$ age in years. 


\section{References}

${ }^{1}$ Earl CJ, Fullerton PM, Wakefield GS, Schutta HS. Hereditary Neuropathy with liability to pressure palsies. $Q J$ Med 1964;33:481-98.

${ }^{2}$ Oh SJ, Sarala PK, Kuba T, Elmore RS. Tarsal tunnel syndrome: electrophysiological study. Ann Neurol 1979;5:327-30.

${ }^{3}$ Fu R, Delisa JA, Kraft GH. Motor nerve latencies through the tarsal tunnel in normal adult subjects: standard determinations corrected for temperature and distance. Arch Phys Med Rehab 1980;61:243-8.

${ }^{4}$ Dekel S, Coates R. Primary carpal stenosis as a cause of "idiopathic" carpal tunnel syndrome. Lancet 1979;i:1024.

${ }^{5}$ Lam SJS. Tarsal tunnel syndrome. J Bone Jt Surg 1967;49B:87-92.

Accepted 2 December 1985

\section{Alteration of the visual blink refiex in patients with dementia}

Sir: The clinical diagnosis of senile dementia of the Alzheimer type and multi-infarct dementia can be very difficult. ${ }^{12}$ Neurophysiological tests are not specific. In a recent study, the EEG and visual evoked potentials were reported to be normal in respectively $34 \%$ and $76 \%$ of patients with Alzheimer type dementia. ${ }^{3}$ Therefore, the development of additional sensitive tests which could discriminate dementia from other disorders, would be of great value.

We have found a simple neurophysiological test, the visual blink refiex, to be abnormal in patients with Alzheimer type dementia or multi-infarct dementia. The visual blink reflex consists of a reflex contraction of the eyelids in response to a bright light which is flashed in front of the eyes of the subject. Normal subjects usually show a visual blink reflex with a constant latency of approximately $50 \mathrm{~ms}$, although the visual blink reflex can be absent in up to $12 \%$ of normals. ${ }^{4}$ The visual blink reflex is a subcortical reflex but the exact pathway in the brainstem is unknown. ${ }^{56}$

Fifteen patients with senile dementia (Alzheimer type dementia or multi-infarct dementia) (mean age $77.2 \pm 7.7 \mathrm{yr}$ ) were examined according to the method described by Malin. ${ }^{4}$ The EMG activity of the orbicularis oculi muscles was recorded with surface skin electrodes. Patients were not informed that the blink reflex was measured in order to avoid voluntary blinking. In each subject we determined the average latency time of the visual blink reflex from 10 trials. The controls were 13 normal aged persons (mean age $70 \cdot 5 \pm 11 \mathrm{yr}$ ).
Twelve out of 15 patients showed a symmetrical visual blink reflex with a mean latency for the group of $104.3 \pm 30.0 \mathrm{~ms}$ (range 65-158 ms). In three patients no visual blink reflex could be elicited. The visual blink reflex of the group of normal subjects had a mean latency of $49 \cdot 7 \pm 2 \cdot 2 \mathrm{~ms}$ (range $47-53.3 \mathrm{~ms}$ ). The visual blink reflex was absent in one control. The mean latencies of the patient and the control group differed significantly $(p<0.001)$.

Our study demonstrates that the latency of the visual blink reflex of patients with senile dementia is markedly increased. Possibly, the alteration of the visual blink reflex in senile dementia is due to lesions or functional disturbances at the level of the brainstem, which are known to occur in Alzheimer type dementia. ${ }^{7}$ In our view these findings imply that further studies on the visual blink reflex in dementia are warranted.

DLJ TAVY

TCAM VAN WOERKOM HHE MORRÉ JPJ SLAETS

Municipal Hospitals, The Hague, Departments of Clinical Neurophysiology and Clinical Neurology and Psychiatric Centre Rosenburg, The Hague, Departments of Neuropsychiatry and Psychogeriatrics $2545 \mathrm{CH}$, The Netherlands

\section{References}

${ }^{1}$ Ron MA, Toone BK, Garalda ME, Lishman WA. Diagnostic accuracy in presenile dementia. Br J Psychiatry 1979;134:161-8.

${ }^{2}$ Caine ED. Pseudodementia. Arch Gen Psychiatry 1981;38:1359-64.

${ }^{3}$ Visser SL, Van Tilburg W, Hooijer C, Jonker C, De Rijke W. Visual evoked potentials (VEPs) in senile dementia (Alzheimer type) and in non organic behavioural disorders in the elderly; comparison with EEG parameters. Electroencephalologr Clin Neurophysiol 1985;60: 115-21.

${ }^{4}$ Malin JP. Der optisch evozierte orbicularis oculi und reflex: methodik, normalwerte, habituation. $Z$ EEG-EMG 1982;13:101-7.

${ }^{5}$ Brierly JB, Graham DI, Adam JH, Simpson JA. Neocortical death after cardiac arrest. Lancet 1971;2:560-5.

${ }^{6}$ Tavy DLJ, Van Woerkom TCAM, Bots GTAM, Endtz LJ. Persistence of the blink reflex to sudden illumination in a comatose patient. Arch Neurol 1984;41:323-4.

${ }^{7}$ Terry RD, Katzman R. Senile dementia of the Alzheimer type. Ann Neurol 1983;14:497-506.

Accepted 10 May 1985
Isolated lower motoneuron involvement fo․ㅡㄹ lowing radiotherapy

Sir: Progressive transverse myelopath which follows, after a characteristic laten period, the radiation of tumours in the vicife ity of the spinal cord is a well-recognised sequel of radiotherapy. ${ }^{1}$ Another myelot pathic post-radiation syndrome is charactes ised by a slowly evolving amyotrophy wit paresis and areflexia of legs withot sphincter disturbances or senso impairment, and is presumed to be the result of selective damage to the anterior horn cellog. in the lumbo-sacral spinal cord. ${ }^{2-4}$

Our case, a 64-year-old male, had a righE sided pheochromocytoma, encasing thes vena cava and the celiac axis. Surgicas removal was only partial, so he receivea 5800 rads to the affected side (December) 1983). Seven months after the treatment, he suffered painful cramps in the legs for two weeks, followed by progressive bilateral leg weakness. There were no sphincter abnoofs malities or sensory symptoms. The course of illness was one of initial worsening followe by a stabilised state until our observation in May 1985. Neurological examination showed diffuse lower limb wasting, repore marked in gluteal muscles, and modertate weakness of the peronei, extensors of the feet and toes and gluteal muscles. Fasencur lations were present in the calf and gl⿶凵⿱乛龰eat muscles. Tendon reflexes were absent inthe legs and plantar responses were flexor. $\mathcal{S e}_{\mathrm{f}}$ sation was intact. Laboratory evaluatipns were normal as well as radiographs of thoracic, lumbar and sacral spine. Magnetic resonance imaging of the thoracolumbat spinal cord was normal, and there was no evidence of intraspinal metastasis. Quap. titative $\mathrm{EMG}^{5}$ of the left vastus medial peroneus longus, gastrocnemius media梁 and lateralis and gluteus maximus showed denervation activity with fasciculations an loss of motor units with pronounced signs of reinnervation in all muscles. Motor condug tion velocity along the left peroneal and post terior tibial nerves was reduced by $24 \%$ and $14 \%$, and distal latencies were prolonged $51 \%$ and $40 \%$ respectively. Amplitudes of motor responses were normal. Amplitude and shape of SAPs sensory thresholds and sensory conduction velocity along the left peroneal and sural nerves were normal. wave latencies were prolonged by $22 \%$ ang $10 \%$ along the left peroneal and posterior tibial nerves respectively; The left $\mathrm{H}$ refles had a prolonged latency, a markedly poly phasic shape, and was constantly associated with late waves at $72 \mathrm{~ms}$. SEPs were obtained in the upper and lower limbs on the 